\title{
EMOCIONES \& EDUCACIÓN. LA CONSTRUCCIÓN HISTÓRICA DE LA EDUCACIÓN EMOCIONAL
}

Por Agustín Escolano Benito. Madrid: Visión Libros, 2018, 243 páginas. ISBN: 978-84-17405-53-3.

Nos encontramos ante otro libro ilustrado de Escolano sobre la educación emocional en perspectiva histórico-educativa y etnográfica, presentado en esta ocasión por Heloísa Helena Pimenta Rocha. Manteniendo el estilo narrativo del autor, con un marcado sello de ensayo, y profundizando en la temática presentada en Scuola ed emozioni. Un nuovo approccio formativo, Emociones \& Educación, este libro se estructura en cuatro capítulos que van abriendo camino de forma conectada a cada uno de los temas abordados: la relación entre la educación y las emociones, la representación de las emociones («en el interior del universo de la escuela», p. 102), la memoria de las emociones, y los climas y dispositivos de las emociones en el contexto específico de la escuela. Los cuatro capítulos están flanqueados por una introducción y una coda a modo de epílogo. Cada comienzo de capítulo, incluida la introducción y la coda, viene acompañado de una bella ilustración que ocupa la página izquierda mostrando a los protagonistas del binomio educación y emociones, o escenas y escenarios educativos con carga emocional. La más impactante representa la violencia docente de un maestro y la más tierna muestra una escolar pensativa con una pizarra. El lector es apelado a pensar y sentir. A estas seis ilustraciones del tamaño de una página, se añaden 91 imágenes a color, que recorren el libro, distribuidas entre los seis apartados. Reproducen portadas de libros de texto, páginas de cuadernos escolares, grabados, fotografías, dibujos, viñetas de comics, carteles publicitarios, y fotografías de periódicos, entre otros. Todas estas imágenes se insertan dentro de la narrativa del autor y vienen comentadas. La iconografía da peso al libro creando su propia narrativa y 
estimulando emocionalmente al lector de la obra, quien no puede leer de forma impasible sus páginas. La relevancia de la iconografía en la escuela y su cultura material, como instrumento pedagógico-emocional, ya ha sido destacada por Escolano en otras obras, como, por ejemplo, la exposición y el libro-catálogo Numancia en la escuela. La construcción histórica de un mito secular (2018).

La introducción y el capítulo I establecen la justificación del tema, rescatan a los autores más relevantes del pasado que tuvieron en cuenta las emociones y los sentimientos, y exponen la base teórica neurocientífica en que se apoya la argumentación (Damasio). Las emociones y los sentimientos son claramente distinguidas (pp. 20-21), y en esta reseña se hará referencia sobre todo a las emociones por considerar que los sentimientos, más complejos y sofisticados, requerirían mayor elaboración.

Se podría afirmar que la socialización emocional tiene lugar en diversos contextos micro y macro donde cada protagonista tiene su rol: la familia (rol de hijo/a, hermano/a, padre, madre), las empresas (rol de trabajador/a), los centros religiosos (rol de creyente/practicante), y las instituciones educativas (rol de maestro/a, rol de estudiante). Escolano, indaga, esencialmente, sobre la pedagogía de las emociones y la socialización emocional en el contexto escolar, el entorno donde ocurre «una inmersión escolar» (p. 18) durante varios años del primer ciclo de vida del ser humano, que convierte («metamorfosea», en palabras del autor, p. 18) al niño/a en alumno/a. Enfatiza el lugar de esta socialización y pedagogía emocional en la historia de la educación y hace un reconocimiento al diálogo establecido entre las nuevas disciplinas y la historia de la educación por permitir «indagar en estos silencios de la historia pragmática o efectual del mundo de la educación, la historia que se ha plasmado en la realidad» (p. 53). Opinamos, sin embargo, que el affective turn apunta realmente a dos hechos. Por una parte, a las nuevas tendencias y enfoques investigadores en ciencias ya existentes como la psicología, la sociología y la neurociencia, provocando que objetos y categorías de análisis anteriormente ignorados o estudiados de forma aislada, descontextualizada y ahistórica, ahora se conecten con otros fenómenos, se multi-contextualicen y se reconozca su historia. Por otra, que se compartan esas nuevas tendencias y enfoques con la historia de la educación y la pedagogía, más allá de la interdisciplinariedad. La transdisciplinariedad se evidencia como imprescindible para producir estos saltos 
cualitativos en la forma de enfocar los objetos de estudio, permitiendo a las emociones convertirse en categorías de análisis dentro del proceso histórico-educativo. Ante la premisa de que «la cultura de la escuela es un conjunto holístico de cogniciones y emociones en interacción» (p. 19), el profesor Escolano, estudioso de la cultura escolar, se centra en ese conjunto holístico de experiencias enfocando la dimensión emocional, y descubriendo la existencia de culturas afectivas escolares («climas afectivos específicos», p. 158), construidas por el contexto histórico: político, ideológico y pedagógico, que moldea los tiempos, los espacios, los objetos y las prácticas escolares (hábitos, costumbres, ritos) para la convivencia y la disciplina.

Pero además de examinar la dimensión emocional de estos tiempos, espacios, objetos y prácticas escolares en sus contextos, Escolano va más allá y reflexiona sobre las representaciones de las emociones que se reproducen en nuestra cultura material y sobre los recuerdos que de estos contextos emocionales quedan en nuestra memoria. Su propia labor etnográfica en el Centro Internacional de la Cultura Escolar (CEIN$\mathrm{CE}$ ) le confirma el valor y la relevancia que las emociones tienen en los procesos de aprendizaje y de socialización a lo largo de la vida de las personas. Parte del mérito de la investigación del profesor Escolano en este ámbito en los últimos años reside en la combinación del enfoque de estudio desde arriba y desde abajo. No solo analiza las emociones como «estrategias de persuasión» (p. 110), es decir, como herramientas pedagógicas de persuasión y seducción, y como instrumentos de imposición, «dispositivos del micropoder pedagógico» (p. 178) para la dominación, la vigilancia y el control, sino también las representaciones de todos esos procesos y los recuerdos de la experiencia de recepción de todo ese mundo emocional impuesto y dirigido, así como la huella de dicha experiencia en sus destinatarios.

Precisamente, la forma de recuperar esos recuerdos emocionales, de activar la memoria escolar afectiva, es entrando en contacto con objetos, documentos y espacios escolares que conduzcan hacia o representen los climas emocionales vividos (juegos) y «las prácticas educativas de gobierno emocional de la infancia» (p. 157) (castigos) experimentadas. Pero los recuerdos escolares no solo sirven para recordar la escuela y todo lo que representa (conocimientos, experiencias positivas y negativas), sino que conduce hacia el interior de la persona, hacia su yo 
pasado, el de la infancia. En la novela de Umberto Eco, citada por Escolano, el protagonista que ha perdido la memoria episódica, la va recuperando cuando entra en contacto con objetos que le estimulan sus recuerdos escolares: libros de texto, cuadernos escolares, comics, redacciones... «Es la memoria episódica la que establece un nexo entre lo que somos hoy y lo que hemos sido [...].». ${ }^{1}$ Bodoni ha perdido realmente la memoria autobiográfica, que no es exactamente lo mismo que la episódica, ni necesita la activación de las mismas zonas cerebrales para recuperar la información. ${ }^{2}$ La recuperación de la memoria autobiográfica requiere de un esfuerzo de acceso al yo conceptual, ${ }^{3}$ dentro del cual se accede a emociones pasadas (que han influido en ese yo) y presentes. Constituiría la versión más alejada de la narrativa oficial sobre la escuela en cada contexto.

Particular relevancia adquiere en este aspecto el experimento terapéutico de estimulación intencional de la memoria escolar a enfermos de Alzheimer, con la conclusión de poder categorizar de estímulo emocionalmente competente al universo de la escuela. Otras investigaciones sobre la recuperación de la memoria autobiográfica han demostrado la relevancia del contexto cultural, y el hecho de que estas memorias «express, develop, and maintain culture». ${ }^{4}$ No solo «la variabilidad expresiva de los afectos habla justamente de los condicionamientos culturales», según afirma Escolano (p. 239), sino que estos últimos afectan a la recuperación y expresión de la memoria sobre los primeros:

Research has demonstrated that children and adults from individualistic cultures provide more lengthy, autonomous, detailed, specific, and self-focused autobiographical memories that focus on individual experiences, roles, and emotions, and contain more references to internal states and own roles, preferences, and feelings than those from collectivistic cultures. In contrast, those

\footnotetext{
${ }_{1}^{1}$ Umberto Eco, La misteriosa llama de la reina Loana (Madrid: Debolsillo, 2006), 19.

2 Asaf Gilboa, «Autobiographical and episodic memory—one and the same?: Evidence from prefrontal activation in neuroimaging studies», Neuropsychologia 42, no. 10 (2004): 1336-1349.

${ }^{3}$ Martin A. Conway y Laura Jobson, "On the nature of autobiographical memory», en Understanding autobiographical memory: Theories and approaches, eds. Dorthe Berntsen y David C. Rubin (Cambridge \& New York: Cambridge University Press, 2012), 54-69.

${ }^{4}$ Conway y Jobson, «On the nature of autobiographical memory», 58.
} 
from collectivistic cultures provide relatively skeletal accounts of past experiences that focus on collective activities, general routines, emotionally neutral events, social interactions, and daily routines. ${ }^{5}$

Estos descubrimientos se relacionan con los estudios de Escolano, pues corroboran la relevancia de sus investigaciones dentro de la historia de la educación y su potencial para investigaciones en otras ciencias, como la psicología (también la social). Las investigaciones de Escolano podrían tener proyección internacional y comparada para descubrir la existencia de patrones diferentes o similares en las representaciones de los escenarios emocionales escolares (cultura material) y en los recuerdos sobre la escuela en sujetos de otros países y épocas (oralidad, testimonios). La vergüenza y el aburrimiento, por ejemplo, ya han sido estudiados por investigadores somo Meda, ${ }^{6}$ en Italia y Sobe, ${ }^{7}$ en los Estados Unidos.

Escolano cierra el libro con una coda que nos recuerda a Dewey: «Experiencia y educación». No es gratuito el guiño pues conocemos "The Theory of Emotion» y las continuas referencias a lo emocional en Democracia y Educación: "La comunicación que asegura la participación en una inteligencia común es la que asegura disposiciones emocionales e intelectuales semejantes, como modos de responder a las expectaciones y a las exigencias». ${ }^{8} \mathrm{Si}$ bien es cierto que las emociones positivas y negativas pueden contribuir o bloquear el aprendizaje, el estudio de Escolano no repara en ese aspecto, sino en la trasposición didáctica o a-didáctica, en la penetración, imposición, inserción y absorción de las diversas emociones en la vida, los espacios, los tiempos, y las prácticas de la escuela.

\footnotetext{
5 Conway y Jobson, «On the nature of autobiographical memory», 62 y 63.

6 Juri Meda, «Vergogna. Storia culturale di un'emozione scolastica: un primo approccio crítico», en Imágenes, discursos y textos en Historia de la Educación [Libro de resúmenes]: Retos metodológicos actuales. XIX Coloquio de Historia de la Educación (El Escorial, Madrid, 2017), 424-427.

7 Noah W. Sobe. «Boredom and Classroom Design: The Affective Economies of School Engagement», en Making Education: Material School Design and Educational Governance, eds. Ian Grosvenor y Lisa Rosén Rasmussenn (Cham, Switzerland: Springer. Educational Governance Research book series, Vol. 9, 2018), 157-169.

8 John Dewey, Democracia y educación. Una introducción a la filosofía de la educación (Madrid: Morata, 1997 [1916]), 16. Traducción de Lorenzo Luzuriaga.
} 
Emociones y Educación forma parte de la producción del profesor Escolano sobre la cultura escolar material e inmaterial de la escuela. Escrita con un estilo de ensayo, y a la vez un informe sobre su experiencia etnográfica en el CEINCE, realiza una revisión de la historia de la educción, la historia de la escuela y la cultura escolar con las emociones y los sentimientos como hilos conductores de trasfondo. Pero, además, contribuye a la historia de las emociones dando a conocer una parcela concreta como es la historia de las emociones en la escuela, complementando trabajos como los de Pekrun, Muis, Frenzel y Goetz, Emotions at School. ${ }^{9}$ Respondería, por tanto, de forma afirmativa a la pregunta que se hace Chiara Meta, "Le emozioni hanno una storia? Ipotesi e nuovi percorsi degli studi storico-educativi». Señala Meta, aludiendo a los estudios historiográficos en Italia, ${ }^{10}$ que «l'emozione intesa come oggetto storico e come dispositivo contingente fatto di sentimenti e norme, che, come abbiamo visto, hanno una storia, variano nel tempo e nello spazio culturale [...]». ${ }^{11}$ Escolano, contribuyendo a las nuevas tendencias de la investigación histórico-educativa, rescata y hace visible la historia de las emociones en la escuela.

Kira Mahamud Angulo Universidad Nacional de Educación a Distancia (UNED) kmahamud@edu.uned.es

\footnotetext{
${ }_{9}$ Reinhard Pekrun, Krista R. Muis, Anne C. Frenzel y Thomas Goetz, Emotions at school (New York \& London: Routledge/Taylor \& Francis Group, 2018).

${ }^{10}$ Cita a C. Covato, «Oggetti, metodologie e tendenze attuali nella storia dell'educazione. Emozioni, passioni e setimente», en La ricerca pedagogica nell'Italia contemporanea. Problemi e prospettive, eds. Giuseppe Bertagna y Simonetta Ulivieri (Roma: Studium, 2017), 112-127.

${ }^{11}$ Chiara Meta, «Le emozioni hanno una storia? Ipotesi e nuovi percorsi degli studi storico-educativi», History of Education and Children's Literature XIII, no. 1 (2018): 661.
} 